\title{
Secretion of an Articular Cartilage Proteoglycan-degrading Enzyme Activity by Murine T Lymphocytes In Vitro
}

\author{
Gary M. Kammer, Asher I. Sapolsky, and Charles J. Malemud \\ Department of Medicine, Division of Rheumatic Diseases, and Department of Developmental Genetics and Anatomy, Case Western \\ Reserve University School of Medicine, Cleveland, Ohio 44106; and Department of Laboratory Medicine and Pathology,
}

Miriam Hospital, Brown University School of Medicine, Providence, Rhode Island 02906

\begin{abstract}
Destruction of articular cartilage is the hallmark of inflammatory arthritides. Enzymes elaborated by mononuclear cells infiltrating the synovium mediate, in part, the degradation of the cartilage extracellular matrix. Since mononuclear cells are the dominant cell type found in chronic inflammatory synovitis, we investigated whether interaction of immune mononuclear cells with antigen initiated the synthesis and secretion of a proteoglycan-degrading enzyme activity. Proteoglycan-degrading enzyme activity was monitored by the capacity of murine spleen cell conditioned medium to release $\left[{ }^{3} \mathrm{H}\right]$ serine/ ${ }^{35} \mathrm{SO}_{4}$ incorporated into rabbit cartilage proteoglycan monomer fraction (A1D1), and by the relative change in specific viscosity of bovine nasal cartilage proteoglycan monomer. The results demonstrated that both virgin and immune mononuclear cells spontaneously generated proteoglycan-degrading enzyme activity and that cellular activation and proliferation induced by the antigen keyhole limpet hemocyanin or the mitogen phytohemagglutinin was not required. Kinetic studies demonstrated stable release of the enzyme activity over $72 \mathrm{~h}$. Cell separation studies showed that $T$ lymphocytes, a thymoma line, and macrophages separately produced proteoglycan-degrading enzyme activity. The enzyme activity has been partially characterized and appears to belong to a class of neutral pH metaldependent proteinases. These observations, the first to demonstrate that $T$ lymphocytes secrete an enzyme capable of degrading cartilage proteoglycan, raise the possibility that this enzyme activity contributes to cartilage extracellular matrix destruction in vivo. Moreover, these data support the conclusion that production of this enzyme by $T$ lymphocytes is independent of an antigen-specific stimulus.
\end{abstract}

\section{Introduction}

Destruction of articular cartilage is the hallmark of inflammatory arthritides. The acidic and neutral proteinases elaborated by the mononuclear cells that infiltrate the synovium appear to mediate the degradation of cartilage. This view is supported by the observations that the secretion of several hydrolytic enzymes is induced by agents that participate in the local immune response and in inflammation such as lymphokines

Dr. Kammer was a Daland Fellow of the American Philosophical Association. Address reprint requests and correspondence to Dr. Kammer, Department of Medicine, Case Western Reserve University, 2074 Abington Rd., Cleveland, OH 44106.

Received for publication 23 January 1985.

J. Clin. Invest.

(c) The American Society for Clinical Investigation, Inc. 0021-9738/85/08/0395/08 \$1.00

Volume 76, August 1985, 395-402
(1-5), endotoxin (6), immune complexes (7), and group A streptococcal cell wall products (8). Thus, the capacity of immune mononuclear cells to secrete a proteinase capable of degrading proteoglycans (PGs) ${ }^{1}$ at neutral $\mathrm{pH}$ may be particularly significant. Mammalian-type collagenase, elastase, and PG-degrading enzymes derived from macrophages $(9,10)$, polymorphonuclear leukocytes $(11,12)$, rheumatoid synovium (13), chondrocytes (14), and synovial cell cultures (15) appear as likely candidates in the causation of articular cartilage extracellular matrix degradation.

Although the antigen(s) responsible for the initiation and perpetuation of a chronic inflammatory synovitis remain largely unknown, certain reactive arthritides have been associated with bacterial diseases that precede the onset of synovitis (reviewed in reference 16). It has been postulated that retained bacterial components, present in an immunogenetically susceptible host, could induce synovitis. Since mononuclear cells, in particular $T$ lymphocytes (17), are the principle cellular type comprising the chronic inflammatory synovitis, we asked whether antigen-specific stimulation of immune mononuclear cells would induce the elaboration of a PG-degrading enzyme. The results demonstrated that $(a)$ both splenic $\mathrm{T}$ lymphocytes and macrophages elaborated a PG-degrading enzyme activity; (b) $\mathbf{T}$ lymphocytes and macrophages produced a constant amount of enzyme activity over $72 \mathrm{~h} ;(c)$ neither antigen nor mitogen augmented the secretion of the enzyme activity by $T$ lymphocytes or macrophages; $(d)$ a thymoma line also secreted a similar enzyme activity; and (e) the PG-degrading activity was partially characterized as a neutral $\mathrm{pH}$ metal-dependent proteinase. These experiments demonstrated that $\mathrm{T}$ lymphocytes secrete a proteoglycanase independent of an antigenic stimulus. This is the first demonstration that $T$ lymphocytes secrete a PG-degrading enzyme in vitro.

\section{Methods}

Reagents. The following principal reagents, chemicals, and isotopes were purchased and used in this study: monoclonal anti-murine/ human MAC-1 (M1/70 HL) (Hybritech, San Diego, CA); fluorescein isothiocyanate (FITC)-F $\left(\mathrm{ab}^{\prime}\right)_{2}$ goat anti-rat IgG (fluorescein to protein molar ratio, $3.68 \mathrm{mg} / \mathrm{g}$ ) (Cappel Laboratories, Cochranville, PA) adsorbed with mouse IgG and IgM (18); anti-Thy 1.2 (gift of Dr. N. Reiner, University of British Columbia, Vancouver, British Columbia, Canada); FITC-anti-Thy 1.2 (New England Nuclear, Boston, MA); keyhole limpet hemocyanin (KLH; Calbiochem-Behring Corp., San Diego, CA); pepstatin, lactalbumin hydrolysate, phenylmethylsulfonyl fluoride, and 1,10-phenanthroline (Sigma Chemical Co., St. Louis,

1. Abbreviations used in this paper: APMA, P-aminophenylmercuric acetate; AT/FBS, acid treated fetal bovine serum; FITC, fluorescein isothiocyanate; ISC, immune spleen cells; $\mathrm{KLH}$, keyhole limpet hemocyanin; PG, proteoglycan(s); PHA, phytohemagglutinin; SBTI, soybean trypsin inhibitor; VSC, virgin spleen cells. 
MO); $P$-aminophenylmercuric acetate (APMA; Aldrich Chemical Co. Milwaukee, WI); guanidine $\mathrm{HCl}$ (Bethesda Research Laboratories, Bethesda, MD); trypsin and soybean trypsin inhibitor (SBTI; Worthington Biochemicals, Freehold, NJ); 6-aminohexanoic acid (Eastman Kodak Co., Rochester, NY); CsCl and EDTA (Fisher, Fairlawn, NJ); RPMI-1640 and Hanks' balanced salt solution (HBSS; Gibco Laboratories, Grand Island, NY); and fetal bovine serum (FBS; Reheis Co., Phoenix, AZ, and KC Biological, Lanexa, KS). [ $\left.{ }^{3} \mathrm{H}\right]$ Methyl-thymidine $\left(\left[{ }^{3} \mathrm{H}\right] \mathrm{TdR}, 6.7 \mathrm{Ci} / \mathrm{mmol}\right),\left[{ }^{3} \mathrm{H}\right]$ serine $(18.5 \mathrm{Ci} / \mathrm{mmol})$, and $\mathrm{Na}_{2}{ }^{35} \mathrm{SO}_{4}$ $(600-800 \mathrm{mCi} / \mathrm{mmol})$ were purchased from New England Nuclear.

The thymoma line BW5147.G.1.4. that is $\mathrm{H}-2^{k}$ and Thy $1.1^{+}$was kindly provided by Dr. T. Kresina, Case Western Reserve University, and was originally obtained from the Salk Institute, San Diego, CA.

Animals. Female or male A/ST mice (West Seneca, Buffalo, NY) between 5 and 8 wk of age were immunized intraperitoneally with $\mathrm{KLH}(50 \mu \mathrm{g})$ emulsified in complete Freund's adjuvant and killed 68 wk later.

Isolation of spleen cells and cell fractionation techniques. Spleens were aseptically resected from virgin or KLH-immunized mice, and single cell suspensions prepared. After centrifugation through Ficoll/ Metrizoate density gradients, the mononuclear cell preparation was $94 \%$ viable by ethidium bromide-acridine orange supravital dye staining. Total mononuclear cell population consisted of $43 \pm 6 \% \mathrm{mIg}^{+}$B cells, $38 \pm 4 \%$ Thy $1.2^{+} \mathrm{T}$ cells, and $9 \pm 2 \%$ macrophages as evidenced by staining with the anti-MAC-1 monoclonal antibody ( $\overline{\mathrm{x}} \pm$ SEM, $n=6$ ).

A macrophage depleted, $T$ cell-enriched cell preparation was obtained by a modified technique adopted to ensure elimination of the adherent, MAC- $1^{+}$macrophage population (19). Mononuclear cells were initially plated at $5 \times 10^{6} / \mathrm{ml}$ on $100 \times 15$-mm plastic tissue culture dishes, and incubated at $37^{\circ} \mathrm{C}$ for $4 \mathrm{~h}$ in $5 \% \mathrm{CO}_{2} / 95 \%$ air. The nonadherent cells were then incubated on nylon wool columns at $37^{\circ} \mathrm{C}$ for $60 \mathrm{~min}$. The effluent nonadherent cells were plated at $2 \times 10^{6} / \mathrm{ml}$ in 24-well culture plates (Linbro; Flow Laboratories, McLean, VA) overnight at $37^{\circ} \mathrm{C}$ in $5 \% \mathrm{CO}_{2} / 95 \%$ air. After recovery of the nonadherent cells, 5 $\times 10^{6}$ cells were treated with anti-MAC- $1(5 \mu \mathrm{g} / \mathrm{ml})$ for $30 \mathrm{~min}$ at $4^{\circ} \mathrm{C}$, washed, then exposed to rabbit serum containing complement (1:5) for $60 \mathrm{~min}$ at $37^{\circ} \mathrm{C}$. The resultant cell population contained $89 \pm 5 \%$ Thy $1.2^{+} \mathrm{T}$ cells, $1.2 \pm 0.9 \% \mathrm{mIg}^{+} \mathrm{B}$ cells, and $0 \% \mathrm{MAC}-1^{+}$ cells $(\overline{\mathrm{x}} \pm \mathrm{SEM}, n=6)$.

In other experiments, a $T$ lymphocyte-enriched preparation was stained with FITC-anti-Thy 1.2, and a population containing $100 \% \mathrm{~T}$ lymphocytes was obtained by fluorescence sorting (FACS IV, BectonDickinson \& Co., Sunnyvale, CA).

The isolation and fractionation of splenic cells were carried out in HBSS supplemented with $10 \mathrm{mM}$ Hepes and $1 \%$ acid treated, heat inactivated fetal bovine serum (AT/FBS) (20). Acid treatment of FBS is required to denature $\alpha_{2}$-macroglobulin, an endogenous serum inhibitor of neutral pH PG-degrading activity $(14,15) .2 \times 10^{6}$ cells/ml were incubated overnight in RPMI-1640 supplemented with $10 \mathrm{mM}$ Hepes, $2 \mathrm{mM}$ L-glutamine, $10 \mu \mathrm{g} / \mathrm{ml}$ gentamicin, $7.5 \%$ sodium bicarbonate, and $0.2 \%$ lactalbumin hydrolysate, buffered to $\mathrm{pH} 7.4$. Lactalbumin hydrolysate replaced AT/FBS since preliminary experiments demonstrated that PG-degrading activity was undetectable in the presence of any serum components, even after preincubation of spleen cell supernatants with trypsin.

$K L H$ - and phytohemagglutinin (PHA)-induced cellular proliferation assay. In this series of experiments, the KLH induced T lymphocyte proliferative response was used as a model of an antigen-dependent system in order to test the hypothesis that antigen-specific stimulation of immune mononuclear cells would induce the secretion of a PGdegrading enzyme. The KLH- and PHA-induced cellular proliferative responses were carried out in RPMI-1640 supplemented with $10 \mathrm{mM}$ Hepes, $2 \mathrm{mM}$ L-glutamine, $10 \mu \mathrm{g} / \mathrm{ml}$ gentamicin, $5 \times 10^{-5} \mathrm{M}$ 2-mercaptoethanol, and $10 \%$ AT/FBS as previously described (19).

\section{Preparation of $P G$ substrates}

Rabbit articular cartilage newly synthesized PG. Four New Zealand white immature rabbits were killed by $\mathrm{N}_{2}$ euthanasia. The shoulder, knee, and hip articular cartilage from each animal was removed and pooled. The cartilage was incubated with testicular hyaluronidase (0.05\%) (Worthington Biochemicals, Freehold, NJ) for $3 \mathrm{~min}$ at room temperature to remove blood cells and synovial mucin, which contaminate the surface of the cartilage (21). The tissue was then incubated in Dulbecco's modified Eagle's medium $\left(\mathrm{MgCl}_{2}, 165 \mathrm{mg} /\right.$ liter substituted for $\mathrm{MgSO}_{4}$ ) containing $10 \%$ FBS, penicillin-streptomycin $(100 \mathrm{U} / \mathrm{ml}$ and $100 \mu \mathrm{g} / \mathrm{ml}$, respectively), $0.1 \%$ mycostatin, $1 \%$ fungizone (Amphotericin $\mathrm{B})$, and $\left[{ }^{3} \mathrm{H}\right]$ serine $(10 \mu \mathrm{Ci} / \mathrm{ml})$ and $\mathrm{Na}_{2}{ }^{35} \mathrm{SO}_{4}(10 \mu \mathrm{Ci} / \mathrm{ml})$, for $20 \mathrm{~h}$ at $37^{\circ} \mathrm{C}$. After addition of supplements, the total inorganic $\mathrm{SO}_{4}$ content of the medium was 12-13 mg/liter (22).

Pooled articular cartilage was extracted according to the single-step dissociation technique of Hascall and Sajdera (23). Proteinase inhibitors (24) were added to $4 \mathrm{M}$ guanidine $\mathrm{HCl}$ to reduce proteolysis during extraction. The extract was clarified by centrifugation and the supernatant dialyzed overnight at $4^{\circ} \mathrm{C}$ in dialysis membranes with $6,000-$ 8,000-mol wt cutoff (Spectrum Medical Industries, Los Angeles, CA) against double distilled deionized water. The resulting dialyzed solution was centrifuged to remove any debris. The clear supernatant was subjected to isopycnic $\mathrm{CsCl}$ density gradient ultracentrifugation under associative conditions $(0.5 \mathrm{M}$ guanidine $\mathrm{HCl} / 0.1 \mathrm{M}$ sodium acetate, $\mathrm{pH} 5.8, \rho_{\mathrm{o}}=1.6 \mathrm{~g} \mathrm{CsCl} / \mathrm{ml}$ ) for $71 \mathrm{~h}$ at $10^{\circ} \mathrm{C}$ and 81,908 , $\mathrm{gav}$. The bottom fourth of the gradient (final density $=1.69 \mathrm{~g} / \mathrm{ml}$ ) contained $64.4 \%$ of the ${ }^{3} \mathrm{H}$ and $84 \%$ of the ${ }^{35} \mathrm{SO}_{4}$. This $\mathrm{Al}$ fraction was then subjected to a second $\mathrm{CsCl}$ density gradient ultracentrifugation, this time under dissociative conditions (4 M guanidine $\mathrm{HCl} / 0.1 \mathrm{M}$ sodium acetate, pH $5.8\left(\rho_{\mathrm{o}}=1.5 \mathrm{CsCl} \mathrm{g/ml}\right)$ to yield the PG monomer (A1D1) used in these experiments. The bottom fourth of the gradient tube (A1D1) contained $95 \%$ of the total initial radioactivity in the dissociative $\mathrm{CsCl}$ gradient. The A1D1 fraction was dialyzed free of guanidine $\mathrm{HCl}$ and freeze dried.

The radiolabeled PG monomer AID1 fraction was chromatographed on Sepharose CL-2B $(0.4 \times 110 \mathrm{~cm})$ and eluted with $4 \mathrm{M}$ guanidine $\mathrm{HCl} / 0.1 \mathrm{M}$ sodium acetate, $\mathrm{pH}$ 5.8. The profile of uronic acid (carbazole reactivity), as measured by the method of Bitter and Muir (25), and radioactivity, eluted as single peak with an average partition coefficient of 0.26 . The remainder of the radiolabeled A1D1 was incorporated into polyacrylamide beads according to the method of Dingle et al. (26). A total of $7.7 \mathrm{~g}$ of beads were recovered from $15 \mathrm{~g}$ of acrylamide. One lot of beads was used throughout the experiments.

Bovine proteoglycan. PG was prepared from bovine nasal septum cartilage by the single-step second dissociative procedure of Hascall and Sajdera (23). The method yields material consisting of PG subunit and a variable amount of $P G$ aggregate. This preparation can be used as a substrate for comparative assays, provided the same PG preparation is used in all the assays, and is the case with respect to the results of experiments reported below.

\section{$P G$-degrading enzyme assays.}

PG-degrading enzyme activity of spleen cell, T lymphocyte, and macrophage culture medium supernates was measured by the release of radiolabeled rabbit PG monomer (A1D1) incorporated into polyacrylamide beads. The release of radiolabeled rabbit A1D1 incorporated into polyacrylamide beads was dependent on the PG fragment size produced by incubation with culture medium and also measured for the ability of these culture media to degrade newly synthesized PG and endogenous articular cartilage. In selected experiments, PG-degrading activity was also assayed by a microviscometry technique using bovine PG. Because of the sensitivity of this assay to even small changes in PG size, we employed this technique to determine the presence of constitutive enzyme activity in culture supernates.

(a) Polyacrylamide beads. Total cell culture supernates from splenic cells were collected every $24 \mathrm{~h}$ over a 72 -h period. The culture medium was immediately frozen in dry ice acetone and freeze dried. The freezedried medium was weighed and redissolved $(65-100 \mathrm{mg} / \mathrm{ml})$ in 50 $\mathrm{mM}$ Tris- $\mathrm{HCl}, \mathrm{pH} 7.25$, containing $0.02 \%$ sodium azide, and dialyzed in membranes with a 2,000 -mol wt cutoff against $50 \mathrm{mM}$ Tris- $\mathrm{HCl}$, $0.5 \mathrm{mM} \mathrm{CoCl}_{2}$, and $0.02 \%$ sodium azide (15) overnight at $4^{\circ} \mathrm{C}$. In 
previous studies (15), dialysis of culture media against buffer containing either $\mathrm{Co}^{2+}$ or $\mathrm{Zn}^{2+}$ was shown to preserve the PG-degrading enzyme activity derived from chondrocyte cultures more effectively than dialysis against buffer containing $\mathrm{Ca}^{2+}$. Dialyzed culture was assayed directly after dialysis.

A portion of the medium was treated with pancreatic trypsin (100 $\mu \mathrm{g} / \mathrm{ml}$ ) for $10 \mathrm{~min}$ at $37^{\circ} \mathrm{C}$ followed by a fivefold excess of SBTI. A separate aliquot was incubated with buffer. Varying amounts (100$500 \mu \mathrm{l})$ of nonactivated or trypsin-antitrypsin-activated concentrated cell culture supernates were incubated with the radiolabeled A1D1 $(0.5$ $\mathrm{ml}$, corresponding to 1,196 and $1,163 \mathrm{cpm}$ of ${ }^{3} \mathrm{H} /{ }^{35} \mathrm{SO}_{4}$, respectively, for $20 \mathrm{~h}$ at $37^{\circ} \mathrm{C}$ ). The resulting released radioactivity was separated from ungraded substrate (26) and an aliquot of the supernatant added to Aquasol. Radioactivity was measured in a Packard-Searle scintillation counting system (model 3255 ) using a ${ }^{3} \mathrm{H} /{ }^{14} \mathrm{C}$-channel.

The results were expressed as percentage release of radioactivity per $10^{6}$ cells from the initial radioactivity in the reaction tube. In all experiments, appropriate controls were included: trypsin $(100 \mu \mathrm{g} / \mathrm{ml})$, trypsin $(100 \mu \mathrm{g} / \mathrm{ml})$ plus SBTI $(500 \mu \mathrm{g} / \mathrm{ml})$, chondrocyte conditioned medium $(500 \mu \mathrm{l})(15)$, RPMI-1640 supplemented with $0.2 \%$ lactalbumin hydrolysate, or buffer blanks. Release of radioactivity from the beads by splenic conditioned medium was considered to be specific when splenic culture media supernates released more radioactivity than the trypsin plus SBTI control group. SBTI itself contained no proteolytic or inhibitory activity against the radiolabeled rabbit cartilage A1D1. In all experiments, ${ }^{3} \mathrm{H}$ and ${ }^{35} \mathrm{SO}_{4}$ was released from radiolabeled A1D1 in proportion to the amount of radioactivity in the starting reaction. This indicated that the results obtained were due to core protein degradation, and not to release of ${ }^{35} \mathrm{SO}_{4}$ alone, as a consequence of endoglycosidases in the splenic cell conditioned medium.

(b) Microviscometry. Medium fractions were dissolved in minimal

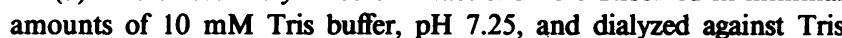
buffer. $200 \mathrm{U}$ of penicillin and $250 \mu \mathrm{g}$ of streptomycin were maintained in all samples. Dialyzed samples or blanks $(150 \mu \mathrm{l})$ were incubated with $150 \mu \mathrm{l}$ of bovine nasal PG $(10 \mathrm{mg} / \mathrm{ml})$. The incubation took place directly in the microviscometer, and the breakdown of proteoglycan was monitored as previously described (27).

Activators (trypsin, vide supra) or APMA $(0.5 \mathrm{mM})$ were made to pH 7.25 and were preincubated with the samples or blanks at room temperature for $15 \mathrm{~min}$ before being mixed with proteoglycan. PGdegrading enzyme activity as a function of $\mathrm{pH}$ was assayed at $\mathrm{pH} 4.5-$ 6.6 (50 mM sodium acetate) and $\mathrm{pH} 7.0-7.5$ (50 mM Tris- $\mathrm{HCl}$ ). The effect of adding 1,10 phenanthroline $(5 \mathrm{mM})$ to trypsin-antitrypsin or APMA activated samples was measured as previously described (15).

The percentage loss of viscosity obeys second-order kinetics (27). A second-order rate constant $(K)$ was obtained by the use of the relation $t^{-1}\left(n_{0}-n_{t}\right) / n_{0}-n_{\infty}$ in units per hour, where $n_{0}, n_{t}$, and $n_{\infty}$ are the substrate flow times at time $0, t$, and complete digestion. For example, when the change from $n_{0}$ to $n_{\infty}$ is $50 \%$ complete in $1 \mathrm{~h}$, the rate constant, $K$, equals one, and when $75 \%$ complete, $K$ equals three.

Statistics. Statistical significance $(P<0.05)$ was calculated by the Fisher's exact test.

\section{Results}

Virgin and immune spleen cells (ISC) produce a proteinase capable of degrading $P G$ monomer. Supernates derived from either virgin or ISC contained an enzyme activity capable of degrading rabbit articular cartilage PG monomer. This was established by culturing unfractionated virgin or KLH-immune spleen cells in serum-free medium in the absence or presence of PHA or KLH over $72 \mathrm{~h}$. The results, summarized in Table I, demonstrated that all of the trypsin-antitrypsin-activated concentrated supernates harvested at $24 \mathrm{~h}$, whether or not derived from virgin or KLH-ISC, released $8.4-10.9 \%$ of the radiolabeled PG from the polyacrylamide bead matrix. This compares with a release of $22.6 \%$ by trypsin alone (Table I).
Table I. Virgin and Immune Murine Spleen Cells That Produced Similar Quantities of PG-degrading Enzyme Activity After 24 h of Culture*

\begin{tabular}{lc}
\hline Preparation & $\begin{array}{l}\text { Percentage of radiolabeled PG } \\
\text { released per } 10^{6} \text { cells }\end{array}$ \\
\hline Controls & \\
Buffer blank & $1.2 \pm 0.3$ \\
Trypsin & $22.6 \pm 0.4$ \\
Trypsin + SBTI & $3.4 \pm 0.7$ \\
Trypsin-activated supernatesł & \\
VCS + media & $9.1 \pm 0.6$ \\
ISC + media & $10.9 \pm 0.6$ \\
VSC + KLH & $9.4 \pm 1.2$ \\
ISC + KLH & $8.4 \pm 0.2$ \\
VSC + PHA & $9.1 \pm 0.1$ \\
ISC + PHA & $8.9 \pm 0.9$ \\
Nonactivated supernatesł & \\
VSC + media & $3.4 \pm 0.3$ \\
ISC + media & $2.7 \pm 0.4$ \\
VSC + KLH & $3.8 \pm 0.8$ \\
ISC + KLH & $2.1 \pm 0.3$ \\
VSC + PHA & $3.2 \pm 0.3$ \\
ISC + PHA & $3.1 \pm 0.1$ \\
\hline
\end{tabular}

* $\overline{\mathrm{x}} \pm \mathrm{SEM}$ of four independent experiments.

$¥$ Comparison of the percentage of radiolabeled PG released between trypsin-activated and nonactivated supernates gave $P<0.007$ in each group (e.g., ISC + media [trypsin activated] vs. ISC + media [nonactivated]).

Nonactivated concentrated supernates released no more radioactivity than the trypsin plus SBTI control group. Addition of SBTI resulted in $85 \%$ inhibition of trypsin activity against radiolabeled A1D1. Based upon this result, we inferred the presence of a latent PG-degrading activity in the various splenic cell culture supernates. Time course experiments demonstrated that the percentage of radiolabeled PG released during each consecutive $24-\mathrm{h}$ interval over the 72 -h period of culture did not differ significantly (Fig. 1, $A$ and $C$ ). Noteworthy was the observation that supernates obtained from either immune or virgin spleen cells (VSC) cultured in the absence of either antigen or mitogen yielded PG-degrading enzyme activity similar to that present in supernates of cells cultured with antigen or mitogen, suggesting that the cells spontaneously produced the enzyme activity and did not require activation by antigen or mitogen to generate the enzyme activity.

Murine spleen cell supernates activated by preincubation with APMA (15) degraded bovine PG as measured in the microviscometry assay. After $24 \mathrm{~h}$ the percentage loss of original viscosity was $41 \%$ (day 1), $40 \%$ (day 2), and $36 \%$ (day 3 ), confirming results of assays using the radiolabeled polyacrylamide beads. However, the microviscometry assay revealed the presence of intrinsic activity against the bovine substrate, not seen with the radiolabeled beads. At this time, we are uncertain whether the sensitivity alone of the viscometric analysis fully accounts for the detection of constitutive PGdegrading enzyme activity.

Bovine PG degradation by spleen cell supernates was assayed as a function of $\mathrm{pH}$. After $1 \mathrm{~h}$ of incubation, maximal activity in the neutral $\mathrm{pH}$ range was seen at $\mathrm{pH} 7.25$, with a 

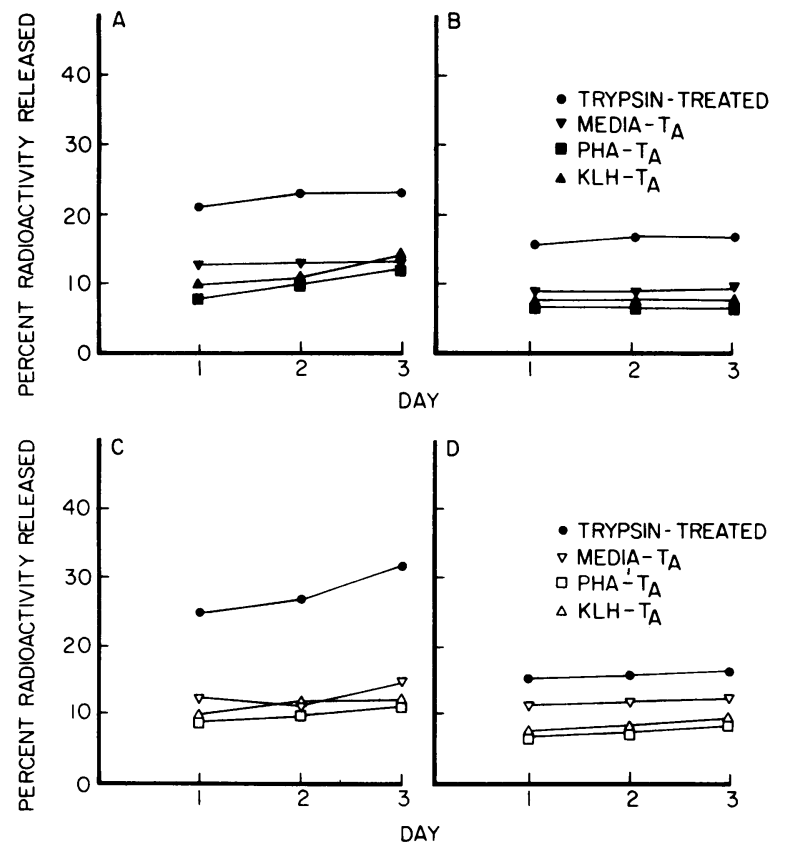

Figure 1. Time course experiments demonstrating percentage radioactivity of A1D1 released from polyacrylamide bead matrix by PGdegrading activity per $10^{6}$ cells derived from $(A)$ virgin or $(C)$ immune splenic mononuclear cells. Mononuclear cells $\left(10^{6} / \mathrm{ml}\right)$ were cultured in serum-free medium in the absence or presence of KLH or PHA, the supernates collected at 24-h intervals over $72 \mathrm{~h}$, and the PG-degrading activity assayed as described in Methods. Virgin and immune mononuclear cells elaborated similar amounts of PG-degrading activity whether or not cultured in the presence of antigen or mitogen. Moreover, the amount present in the concentrated culture medium was essentially constant over $72 \mathrm{~h}$. Enriched $(B)$ virgin and (D) immune splenic $\mathrm{T}$ lymphocytes also generated similar amounts of PG-degrading activity over a 72-h interval when cultured in the absence or presence of antigen or mitogen. $T_{A}$, trypsin-activated cell culture supernates.

sharp dropoff above pH 7.5. At pH 7.25, 1,10 phenanthroline inhibited the PG-degrading enzyme activity by $81.9 \%$. In addition to PG-degrading enzyme activity at $\mathrm{pH}$ 6.6-7.5, activity was also seen in the acid-pH range (pH 4.5-5.9) in a manner similar to that reported by Sapolsky et al. (27) for human patellar cartilage PG-degrading enzyme activity.

An initial question was whether antigen-induced activation of immune mononuclear cells stimulated the synthesis of a proteinase capable of degrading PG monomer. Since the peak proliferative responses of ISC to PHA and KLH are attained at 72 and $96 \mathrm{~h}$, respectively (Table II) (19), the prompt secretion of the proteinase into the supernates suggested a dissociation between the proliferative response to mitogen or antigen and release of the proteinase activity. More importantly, however, the presence of the proteinase activity in supernates from virgin cells not exposed to either mitogen or antigen underscored the apparent independence of this event from cellular blastogenesis.

Macrophages secrete PG-degrading activity. The observation that murine splenic cells elaborated an enzyme activity capable of degrading proteoglycan prompted us to identify the cellular population(s) responsible for its production. To examine adherent accessory cells as a potential source, peritoneal macrophages were selected, since mouse spleens contain only $\sim 8 \%$
Table II. Proliferative Responses of Unfractionated or Macrophage-depleted ISC to KLH and PHA*

\begin{tabular}{lc}
$\begin{array}{l}\text { KLH-immmune spleen } \\
\text { cell preparation }\end{array}$ & $\begin{array}{l}{\left[{ }^{3} \mathrm{H}\right] \mathrm{TdR} \ddagger} \\
(\Delta \mathrm{cpm})\end{array}$ \\
\hline Unfractionated & \\
Media & \\
KLH & $1,877 \pm 104$ \\
PHA & $19,134 \pm 2,064$ \\
Macrophage depleted & $43,748 \pm 4,113$ \\
Media & \\
KLH & $214 \pm 33$ \\
PHA & $405 \pm 61$ \\
FACS-separated & $5,114 \pm 427$ \\
Media & \\
KLH & $175 \pm 12$ \\
PHA & $333 \pm 29$ \\
Macrophage replenished§ & $4,571 \pm 331$ \\
Media & \\
KLH & $1,510 \pm 111$ \\
PHA & $17,930 \pm 1,664$ \\
\hline
\end{tabular}

* $2 \times 10^{5}$ unfractionated splenic mononuclear cells, or $2 \times 10^{5}$ enriched $\mathrm{T}$ lymphocytes alone, or $2 \times 10^{5}$ FACS-separated T lymphocytes, or $2 \times 10^{5} \mathrm{~T}$ lymphocytes and $1 \times 10^{4}$ irradiated, unelicited peritoneal macrophages were cultured in the absence or presence of $\mathrm{KLH}(100 \mu \mathrm{g} / \mathrm{ml})$ for $96 \mathrm{~h}$ or PHA for $72 \mathrm{~h}$ in microtiter wells at $37^{\circ} \mathrm{C}$ in $5 \% \mathrm{CO}_{2} / 95 \%$ air. $18 \mathrm{~h}$ before termination, the cultures were pulsed with $\left[{ }^{3} \mathrm{H}\right]$ thymidine $(1 \mu \mathrm{Ci} /$ well $)$ and the cultures were harvested with a MASH II microculture harvester. Back-ground cpm were subtracted from experimental $\mathrm{cpm}(\Delta \mathrm{cpm})$.

$\ddagger \bar{x} \pm$ SEM of 3-5 independent experiments; FACS separated, two independent experiments.

$\S$ Macrophage replenished, 5\% irradiated unelicited peritoneal macrophages.

of such cells. Unelicited resident peritoneal cells, initially comprised of $87 \pm 2 \%$ MAC- $1^{+}$macrophages, were depleted of nonadherent cells. This enriched adherent cell population, composed of $96 \pm 1.5 \%$ viable MAC $-1^{+}$macrophages $(\overline{\mathrm{x}} \pm$ SEM, $n=3$ ), was cultured as previously described above, but in the absence of serum. The results, shown in Fig. 2, demonstrated that trypsin-antitrypsin-activated supernates derived from resident macrophages also contained an enzyme activity that released $6.6-8.4 \%$ of the radiolabeled A1D1 during each consecutive $24-\mathrm{h}$ interval over a $72-\mathrm{h}$ period. Thus, the time course of proteinase secretion was similar to that of unfractionated splenic cells. We also found that macrophage activation by uptake of latex beads (phagocytosis) (28) did not augment the amount of PG-degrading activity (Fig. 2). In addition, macrophage supernates activated with trypsin-antitrypsin pretreatment resulted in a 4-9\% reduction in bovine PG viscosity after $1 \mathrm{~h}$, and a $12-20 \%$ reduction after $24 \mathrm{~h}$. The enzyme activity was inhibited by $50 \%$ on day 1 and $85 \%$ on day 2 by 1,10 phenanthroline.

$T$ lymphocytes can elaborate PG-degrading activity. Since $\mathrm{T}$ lymphocytes comprise $>70 \%$ of the round cell infiltrate found in the chronic synovitis of rheumatoid arthritis (17), it was pertinent to establish whether or not $T$ lymphocytes were also capable of generating PG-degrading activity. Thus, splenic mononuclear cells were exhaustively depleted of macrophages and B lymphocytes, and the nonadherent virgin or KLH- 


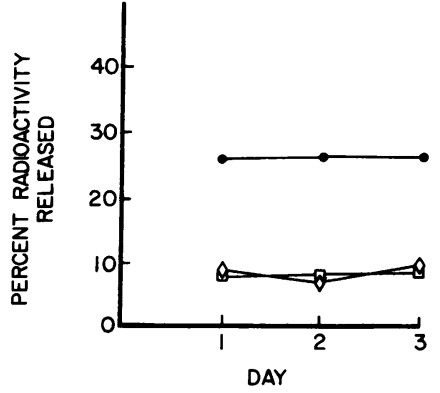

Figure 2. Unelicited resident peritoneal macrophages: time course experiments demonstrating percentage radioactivity of A1D1 released from polyacrylamide bead matrix by PG-degrading activity per $10^{6}$ cells derived from unelicited resident murine peritoneal macrophages. Macrophages $\left(10^{6} / \mathrm{ml}\right)$ were cultured in serum-free medium in the absence or presence of latex beads, the supernates collected at 24-h intervals over $72 \mathrm{~h}$, and the PG-degrading activity assayed as described in Methods. Macrophages cultured in the absence or presence of latex beads elaborated similar amounts of PG-degrading activity over the 72-h period. $T_{A}$, trypsin-activated cell culture supernates. $\bullet$, Trypsin alone; $\square$, media- $T_{A} ; \diamond$, latex beads- $T_{A}$.

immune $\mathrm{T}$ lymphocytes cultured in the absence or presence of PHA or KLH over $72 \mathrm{~h}$, as described above. The concentrated supernates of both virgin and immune $\mathrm{T}$ cell-enriched populations, which contained no $\mathrm{MAC}-1^{+}$macrophages, also possessed a latent, trypsin activatable PG-degrading activity (Fig. 1, B and $D$ ). When the proportion of radiolabeled AID1 released by trypsin-antitrypsin treatment of supernates from virgin or immune splenic $\mathrm{T}$ lymphocytes was compared with that from unfractionated mononuclear cells, $58-82 \%$ was derived from $T$ lymphocytes alone. Such activity was not augmented by the presence of PHA or KLH in culture. Furthermore, like the latent enzyme derived from unfractionated splenic mononuclear cells and from macrophages, time course studies demonstrated that PG-degrading activity was produced continuously over a $72-\mathrm{h}$ period.

The absence of macrophages from the enriched $T$ lymphocyte population was verified by assessing their proliferative responses to KLH and PHA. In the absence of macrophages capable of presenting antigen to immune $T$ cells, there is a failure to mount a $\mathrm{T}$ lymphocyte proliferative response to antigen or mitogen (19). The data, summarized in Table II, indicated that, in the absence of macrophages, enriched immune $T$ lymphocytes failed to proliferate significantly in response to KLH or PHA. However, upon replenishing of T lymphocytes with irradiated $(3,000 \mathrm{rad})$ peritoneal macrophages, the $T$ lymphocyte proliferative response was recovered.

To verify the capacity of T lymphocytes to secrete a PGdegrading activity, the supernates of both FACS-purified splenic $T$ lymphocytes and a thymoma line were examined. The results, summarized in Table III, clearly demonstrated that both normal $\mathrm{T}$ lymphocytes and a malignant thymoma cell line did produce the PG-degrading enzyme activity. Furthermore, the supernates of both FACS-purified splenic T lymphocytes and the thymoma line activated by trypsin-antitrypsin pretreatment also degraded radiolabeled A1D1 in the polyacrylamide bead assay (data not shown).

$T$ lymphocyte $P G$-degrading activity in a metal-dependent neutral proteinase. The recognition that $\mathrm{T}$ lymphocytes generated a PG-degrading enzyme prompted us to partially characterize the activity according to the effect of inhibitory agents on release of $\left[{ }^{3} \mathrm{H}\right]$ serine $/{ }^{35} \mathrm{SO}_{4}$. Table IV summarizes the results of experiments designed to test the effects of various proteinase inhibitors or metal-chelators upon the PG-degrading
Table III. Degradation of Bovine PG Monomer by Thymoma and FACS-purified T Lymphocyte Culture Media

\begin{tabular}{llll}
\hline \multirow{2}{*}{ Group } & & \multicolumn{2}{l}{ Loss in viscosity (\%) } \\
\cline { 3 - 4 } Thymoma & Day & \multicolumn{2}{l}{ Incubation time (h) } \\
& & 1 & 24 \\
& 1 & 0 & 13 \\
FACS-purified T lymphocytes & 2 & 6 & 14 \\
& 3 & 3 & 18 \\
& 1 & 2 & 4 \\
& 2 & 5 & 7 \\
\hline
\end{tabular}

$1 \times 10^{6}$ thymoma cells per milliliter and $1 \times 10^{6}$ FACS-purified T lymphocytes per milliliter were cultured for $3 \mathrm{~d}$ in RPMI-1640 medium supplemented with lactalbumin hydrolysate $(0.2 \%)$, L-glutamine (2 $\mathrm{mM})$, penicillin/streptomycin $(0.1 \%)$, and Hepes $(10 \mathrm{mM})$ made to $\mathrm{pH}$ 7.4. At daily intervals, the total culture medium was withdrawn and freeze dried. Media were activated by trypsin-antitrypsin pretreatment, and percentage loss of viscosity of the bovine PG substrate was assayed as described in Methods. An aliquot of the preactivated supernates assayed was incubated with 1,10-phenanthroline (5 mM) before assay. Due to the sensitivity of the microviscometric technique, trypsin-antitrypsin degraded the proteoglycan to $\sim 25-30 \%$ of the original viscosity, but none of that activity was inhibited by $1,10-$ phenanthroline. Thus, all of the enzyme activity toward proteoglycan in the thymoma and FACS purified, T lymphocyte trypsin-activated medium was due to the neutral $\mathrm{pH}$, metal-dependent enzyme, and not due to residual trypsin activity. The percentage loss in viscosity was calculated by subtracting the percentage loss of units of trypsinantitrypsin activated plus 1,10-phenanthroline-treated supernates, plus that of PG alone ( $2 \mathrm{U}$ at 1 and $24 \mathrm{~h}$ ) from trypsin-antitrypsin activated supernates.

enzyme activity. Phenylmethylsulfonyl fluoride, pepstatin, and 6-aminohexanoic acid did not significantly inhibit the release of radiolabeled A1D1 from the beads. In contrast, both 1,10 phenanthroline and EDTA significantly inhibited release of radioactivity from the beads, indicating the metal dependency for this PG-degrading activity. Analysis of the $\mathrm{pH}$ curve of optimal activity showed that peak activity of the enzyme activity ranged from pH 7.0 to 7.4. These observations demonstrated that one form of the PG-degrading activity secreted by $T$ lymphocytes belonged to the class of enzyme proteins that are metal dependent.

\section{Discussion}

Murine $T$ lymphocytes and macrophages secreted into the culture medium neutral $\mathrm{pH}$, metal dependent, trypsin- and APMA-activatable enzyme activity toward cartilage PG monomer. This is the first documentation of the capacity of $T$ lymphocytes to elaborate such an enzyme activity. The proteinase derives from both virgin and immune splenic $T$ lymphocytes as well as resident peritoneal macrophages. Since elaboration of the enzyme activity does not require cellular activation by either mitogens or antigens to induce its production and secretion, the events regulating its synthesis and secretion appear to be intracellular and do not depend upon exogenous activating signals. This observation would appear to establish that $T$ lymphocytes secrete this PG-degrading 
Table IV. Effect of Potential Inhibitors on the $T$ Lymphocyte PG-degrading Activity

\begin{tabular}{lcc}
\hline Group & Concentration & Activity \\
\hline & & $\%$ \\
Experimental & & \\
Virgin T lymphocytes & $400 \mu \mathrm{l}$ & 100 \\
Virgin T lymphocytes & & \\
$\quad$ + PMSF & $1 \mathrm{mM}$ & 95.5 \\
+ Pepstatin & $10 \mu \mathrm{g} / \mathrm{ml}$ & 95.5 \\
+ Phenanthroline & $5 \mathrm{mM}$ & 51.5 \\
+ EDTA & $10 \mathrm{mM}$ & 35.6 \\
+ 6-Aminohexanoic acid & $0.2 \mathrm{mM}$ & 96.9 \\
Controls & & \\
Buffer & - & 18.2 \\
2-Propanol & - & 19.7 \\
Ethanol & $30 \%$ & 16.6 \\
Trypsin & $100 \mu \mathrm{g} / \mathrm{ml}$ & 84.8 \\
Trypsin + SBTI & $100 \mu \mathrm{g} / \mathrm{ml}, 500 \mu \mathrm{g} / \mathrm{ml}$ & 20.4 \\
\hline
\end{tabular}

Virgin T lymphocyte supernates from three consecutive days were pooled and freeze dried. Approximately $144 \mathrm{ml}$ of supernatant was collected. The freeze-dried medium was redissolved in $20 \mathrm{ml} \mathrm{5-mM}$ Tris- $\mathrm{HCl}, \mathrm{pH} 7.25$, and dialyzed in membranes with a 2,000-mol wt cutoff against three liters of $5-\mathrm{mM}$ Tris- $\mathrm{HCl}, 0.5 \mathrm{mM} \mathrm{CoCl}_{2}, 0.02 \%$ sodium azide, $\mathrm{pH} 7.25$, for $24 \mathrm{~h}$ at $4^{\circ} \mathrm{C}$. The retained material was used and assayed in triplicate without further purification. Trypsin, soybean trypsin inhibitor, 6-aminohexanoic acid, and EDTA were dissolved in buffer; phenylmethylsulfonyl fluoride (PMSF) and pepstatin were dissolved in 2-propanol; and 1,10 phenanthroline was dissolved in $30 \%$ ethanol. Total volume of reaction mixture was $0.5 \mathrm{ml}$.

enzyme activity independent of an antigen-specific stimulus. This inference is further supported by time course studies which demonstrated that the amount of PG-degrading activity detected in the concentrated culture medium supernates was essentially constant over a 72-h interval and could not be augmented by agents that activate $\mathrm{T}$ lymphocytes or macrophages. The enzyme activity belonged to the class of metaldependent neutral proteinases as characterized by optimal activity at neutral $\mathrm{pH}$ and by inhibition by phenanthroline or EDTA, but not by phenylmethylsulfonyl fluoride or 6-aminohexanoic acid. In addition, PG-degrading enzyme activity in the acid pH range was also found but not examined further.

Murine T lymphocyte and macrophage proteoglycanase(s) share certain features, but not others, with the proteoglycandegrading activity elaborated by rabbit macrophages (14) and articular chondrocytes (15) in culture. Like murine T lymphocyte and murine macrophage derived PG-degrading enzyme, one class of rabbit macrophage and chondrocyte PG-degrading enzymes exhibited optimal activity at neutral pH, was inhibited by EDTA, phenanthroline, and serum, but was not blocked by inhibitors of serine proteinases $(29,30)$. Although serine proteinases such as polymorphonuclear leukocyte elastase $(31,32)$ and acid metalloproteinases (33) also degrade PGs, the results shown in Table IV indicated that serine proteinases were not a major contributor to proteolysis in these studies, since $1 \mathrm{mM}$ phenylmethylsulfonyl fluoride, which inhibits macrophage elastolysis by $76 \%$ (34) and rabbit granulocyte PG-degrading enzyme at neutral pH (14), failed to inhibit spleen cell PG-degrading enzyme activity. In addition, Cathepsin D activity has been shown to be present at extracellular sites in rheumatoid synovium (35). In the present experiments, pepstatin failed to inhibit the degradation of the PG substrate. Utilizing the radiolabeled polyacrylamide bead substrate, murine $\mathrm{T}$ lymphocyte and macrophage PG-degrading activity was shown to be latent. The greater sensitivity of the microviscometry assay, however, revealed constitutive PG-degrading activity as well (15).

The amount of radiolabeled proteoglycan released from the polyacrylamide beads by $\mathrm{T}$ lymphocyte culture supernates was only 8-10\% above the trypsin-antitrypsin control group. We have previously shown that release of ${ }^{35} \mathrm{SO}_{4}$ from insoluble substrates such as articular cartilage slices by crude polymorphonuclear leukocyte granule extract (31) or purified neutrophil elastase or Cathepsin G (12) was dependent on the size of the PG fragments released from the substrate. It is unlikely that release of radiolabeled proteoglycan from polyacrylamide beads was low as a result of delayed diffusion of PG-degrading enzyme activity into the bead network, inasmuch as the incubations were carried out for $24 \mathrm{~h}$. A more likely explanation is that proteoglycan must be cleaved in multiple sites along the core protein for maximal release of radioactivity from the substrate to occur. Inasmuch as a similar explanation was deemed appropriate for an understanding of how neutrophil elastase and Cathepsin $\mathbf{G}$ degrades articular cartilage proteoglycan (12), the current results cannot imply any special characteristic of the lymphocyte PG-degrading activity.

In the present study, chondrocyte conditioned medium (15) was used as an additional control. This source, concentrated 18-20-fold, was more potent than spleen cell supernates in releasing radioactivity from the bead substrate $(50.4 \pm 2.4 \%$, $\overline{\mathrm{x}} \pm \mathrm{SEM}, n=10$ ). Nevertheless, concentrated spleen cell supernates released $2.5-4.8$-fold more radiolabeled proteoglycan than substrate incubated with trypsin-antitrypsin. Results obtained with chondrocyte conditioned medium on radiolabeled A1D1 incorporated into beads was similar to those reported by Morales and Kuettner (36), who measured carbazole reactivity (uronic acid) rather than radioactivity. In the present study, however, the spleen cell supernates were concentrated only 1.5-2-fold. Thus, the low level of radioactivity released from the bead substrate by splenic supernates may have also resulted from its inability to produce cleavage products small enough to escape the bead substrate, or from our failure to concentrate the medium sufficiently to maximize PG-degrading activity on this substrate. The latter explanation seems less likely, since trypsin-antitrypsin-activated culture media derived from the thymoma cell line, concentrated 9.5-fold, released 1.5 times the radioactivity from the polyacrylamide beads compared with the trypsin-antitrypsin control group. Nevertheless, release of radioactivity by spleen cells or $\mathrm{T}$ lymphocytes was always significantly higher than any other control group tested, and was frequently similar to the results obtained in the A1D1 plus trypsin incubate. Since it may be inferred from this and other studies that PG-degrading enzymes derived from various cell sources cleave proteoglycans at differing sites on the core protein, a determination of the size of the cleavage products produced by incubation of AIDI with $\mathrm{T}$ lymphocyte PG-degrading enzyme seems warranted in future studies.

The PG-degrading activity derived from $T$ lymphocytes may directly contribute to the pathophysiology of inflammatory 
arthritis. The cellular infiltrate present at the cartilage-pannus interface is similar to that observed elsewhere in the rheumatoid synovium and is primarily composed of macrophages, lymphocytes, and fibroblasts (37). Although the lineage of the lymphocytes at the cartilage-pannus junction remains uncertain, the predominance of $\mathrm{T}$ lymphocytes in rheumatoid synovium $(17,38)$ would suggest that such lymphocytes are also $T$ lymphocytes. Thus, T lymphocyte PG-degrading activity, combined with that derived from pannus macrophages and fibroblasts and that residing within the cartilage itself (15), could participate in a final common pathway resulting in articular cartilage extracellular matrix PG degradation.

In conclusion, our findings reported herein show that murine $\mathrm{T}$ lymphocytes spontaneously elaborate a latent neutral metal-dependent proteoglycan-degrading activity in the absence of extracellular activating signals, which implies that neither the presence of antigen nor activation by other immunologic mechanisms $(39,40)$ is required for enzyme synthesis or secretion.

\section{Acknowledgments}

The authors thank Danielle Duller and Robert S. Papay for their expert technical assistance, and Dr. R. W. Moskowitz for support of these studies.

This work was supported by National Institutes of Health (NIH) Multipurpose Arthritis Center grant AM-20618 and NIH grant AG02205, and by a grant from ICI Americas, Inc.

\section{References}

1. Wahl, L. M., S. M. Wahl, S. E. Mergenhagen, and G. R. Martin. 1975. Collagenase production by lymphokine-activated macrophages. Science (Wash. DC). 187:261-263.

2. Pantalone, R. M., and R. C. Page. 1975. Lymphokine-induced production and release of lysosomal enzymes by macrophages. Proc. Natl. Acad. Sci. USA. 72:2091-2094.

3. Klimetzek, V., and C. Sorg. 1977. Lymphokine-induced secretion of plasminogen activator by murine macrophages. Eur. J. Immunol. 7:185-187.

4. Mizel, S., J.-M. Dayer, S. Krane, and S. Mergenhagen. 1981. Stimulation of rheumatoid synovial cell collagenase and prostaglandin by partially purified lymphocyte-activating factor (interleukin 1). Proc. Natl. Acad. Sci. USA. 78:2474-2477.

5. Evequoz, V., F. Bettens, F. Kristensen, U. Trechsel, B. M. Stadler, J.-M. Dayer, A. L. DeWeck, and H. Fleisch. 1984. Interleukin 2-independent stimulation of rabbit chondrocyte collagenase and prostaglandin $\mathrm{E}_{2}$ production by an interleukin 1-like factor. Eur. J. Immunol. 14:490-495.

6. Wahl, L. M., S. M. Wahl, S. E. Mergenhagen, and G. R. Martin. 1974. Collagenase production by endotoxin-activated macrophages. Proc. Natl. Acad. Sci. USA. 71:3598-3601.

7. Cardella, C. J., P. Davies, and A. C. Allison. 1974. Immune complexes induce selective release of lysosomal hydrolases from macrophages. Nature (Lond.). 247:46-48.

8. Davies, P., R. C. Page, and A. C. Allison. 1974. Changes in cellular enzyme levels and extracellular release of lysosomal acid hydrolase in macrophages exposed to group A streptococcal cell wall substance. J. Exp. Med. 139:1262-1282.

9. Werb, Z., and S. Gordon. 1975. Secretion of a specific collagenase by stimulated macrophages. J. Exp. Med. 142:346-359.

10. Banda, M., and Z. Werb. 1981. Mouse macrophage elastase purification and characterization as a metalloproteinase. Biochem. $J$. 193:589-605.

11. Murphy, G., J. J. Reynolds, U. Bertz, and M. Baggiolini. 1977.
Collagenase is a component of the specific granules of human neutrophil leukocytes. Biochem. J. 162:195-197.

12. Janoff, A., G. Feinstein, C. J. Malemud, and J. M. Elias. 1976. Degradation of cartilage proteoglycan by human leukocyte granule neutral proteases-a model of joint injury. J. Clin. Invest. 57:615624.

13. Woolley, D. E., C. E. Brinckerhoff, C. L. Mainardi, C. A. Vater, J. M. Evanson, and E. D. Harris, Jr. 1979. Collagenase production by rheumatoid synovial cells: morphological and immunohistochemical studies of the dendritic cell. Ann. Rheum. Dis. 38: 262-270.

14. Werb, Z., J. T. Dingle, J. J. Reynolds, and A. J. Barrett. 1978. Proteoglycan-degrading enzymes of rabbit fibroblasts and granulocytes. Biochem. J. 173:949-958.

15. Sapolsky, A. I., C. J. Malemud, D. P. Norby, R. W. Moskowitz, K. Matsuta, and D. S. Howell. 1981. Neutral proteinases from articular chondrocytes in culture. 2 Metal-dependent latent neutral proteoglycanase, and inhibitory activity. Biochim. Biophys. Acta. 658:137-147.

16. Goldenberg, D. L. 1983. "Postinfectious" arthritis: a new look at an old concept with particular attention to disseminated gonococcal infection. Am. J. Med. 74:925-928.

17. Van Boxel, J. A., and S. A. Paget. 1975. Predominantly T-cell infiltrate in rheumatoid synovial membranes. N. Engl. J. Med. 293: 517-520.

18. Springer, T., G. Galfré, D. S. Secher, and C. Milstein. 1979. Mac-1: a macrophage differentiation antigen identified by monoclonal antibody. Eur. J. Immunol. 9:301-306.

19. Kammer, G. M., and E. R. Unanue. 1980. Accessory cell requirement in the proliferative response of $T$ lymphocytes to hemocyanin. Clin. Immunol. Immunopathol. 15:434-443.

20. Werb, Z. 1978. Biochemical actions of glucocorticoids on macrophages in culture. J. Exp. Med. 147:1695-1712.

21. Sokoloff, L., C. J. Malemud, and W. T. Green, Jr. 1970. Sulfate incorporation by articular chondrocytes in monolayer culture. Arthritis Rheum. 13:118-124.

22. Malemud, C. J., and L. Sokoloff. 1971. Failure of rumalon to increase sulfate incorporation by articular chondrocytes in monolayer culture. Arthritis Rheum. 14:779-780.

23. Hascall, V. C., and S. W. Sajdera. 1969. Proteinpolysaccharide complex from bovine nasal cartilage. J. Biol. Chem. 244:2384-2396.

24. Oegema, T. R., Jr., V. C. Hascall, and D. D. Dzietwiatkowski. 1975. Isolation and characterization of proteoglycans from the Swarm rat chondrosarcoma. J. Biol. Chem. 250:6151-6159.

25. Bitter, T., and H. Muir. 1962. A modified uronic acid carbazole reaction. Anal. Biochem. 4:330-334.

26. Dingle, J. T., A. M. J. Blow, A. J. Barrett, and P. E. N. Martin. 1977. Proteoglycan-degrading enzymes: a radiochemical assay method and the detection of a new enzyme, Cathepsin F. Biochem. J. 167: 775-785.

27. Sapolsky, A. I., H. Keiser, D. S. Howell, and J. F. Woessner, Jr. 1976. Metalloproteases of human articular cartilage that digest cartilage proteoglycan at neutral and acid pH. J. Clin. Invest. 50:10301041.

28. North, R. J. 1978. Opinions: the concept of the activated macrophage. J. Immunol. 121:806-809.

29. Hauser, R. J., and G. Vaes. 1978. Degradation of cartilage proteoglycans by a neutral proteinase secreted by rabbit bone-marrow macrophage in culture. Biochem. J. 172:275-284.

30. Malemud, C. J., G. A. Weitzman, D. P. Norby, A. I. Sapolsky, and D. S. Howell. 1979. Metal-dependent neutral proteoglycanase activity from monolayer-cultured lapine articular chondrocytes. J. Lab. Clin. Med. 93:1018-1030.

31. Malemud, C. J., and A. Janoff. 1975. Identification of neutral proteases in human neutrophil granules that degrade articular cartilage proteoglycan. Arthritis Rheum. 18:361-368.

32. Keiser, H. D., R. A. Greenwald, G. Feinstein, and A. Janoff. 
1976. Degradation of cartilage proteoglycan by human leukocyte granule neutral proteases-a model of joint injury. J. Clin. Invest. 57: 625-632.

33. Woessner, J. F., Jr., and M. G. Selzer. 1984. Two latent metalloproteinases of human articular cartilage that digest proteoglycans. J. Biol. Chem. 259:3633-3638.

34. Werb, Z., and S. Gordon. 1975. Elastase secretion by stimulated macrophages: characterization and regulation. J. Exp. Med. 142:361377.

35. Poole, A. R., R. M. Hembry, J. T. Dingle, I. Pinder, E. F. J. Ring, and J. Cosh. 1976. Secretion and localization of cathepsin D in synovial tissues removed from rheumatoid and traumatized joints: an immunochemical study. Arthritis Rheum. 19:1295-1307.

36. Morales, T. I., and K. E. Kuettner. 1982. The properties of the neutral proteinase released by primary chondrocyte cultures and its action on proteoglycan aggregate. Biochim. Biophys. Acta. 705:92101.

37. Kobayashi, I., and M. Ziff. 1975. Electron microscopic studies of the cartilage-pannus junction in rheumatoid arthritis. Arthritis Rheum. 18:475-483.

38. Kurosaka, M., and M. Ziff. 1983. Immunoelectron microscopic study of the distribution of T-cell subsets in rheumatoid synovium. $J$. Exp. Med. 158:1191-1210.

39. Galili, U., L. Rosenthal, N. Galili, and E. Klein. 1979. Activated $\mathrm{T}$ cells in the synovial fluid of arthritic patients: characterization and comparison with in vitro activated human and murine $T$ cells in cooperation with monocytes in cytotoxicity. J. Immunol. 122: 878-883.

40. Galili, U., L. Rosenthal, and E. Klein. 1981. Activated T cells in the synovial fluid of arthritic patients. J. Immunol. 127:430-432. 